\title{
Påliteligheten av selvrapportert alkoholkonsum Svalbardstudien 1988-89
}

\author{
Georg Høyer ${ }^{1}$, Odd Nilssen ${ }^{1}$, Tormod Brenn ${ }^{1}$ og Helge Schirmer ${ }^{2}$ \\ ${ }^{1}$ Institutt for Samfunnsmedisin, Universitetet i Tromsø \\ ${ }^{2}$ Frogner helsesenter, Oslo \\ Korrespondanse til Georg Høyer, Institutt for Samfunnsmedisin, Universitetet i Tromsø, 9037 Tromsø
}

\begin{abstract}
SAMMENDRAG
Svalbard er spesielt godt egnet til å vurdere påliteligheten av selvrapportert alkoholkonsum. På grunn av det lave prisnivået for alkohol er ulovlig import eller hjemmeproduksjon av alkohol ukjent på Svalbard. Dessuten er samfunnet lite og oversiktlig, slik at det er praktisk mulig å undersøke hele befolkningen. I den aktuelle studien registrerte vi alt salg av alkohol til fastboende nordmenn på Svalbard i oktober og november 1988. I samme tidsperiode ble alle nordmenn 18 år eller eldre invitert til å ta del i en helseundersøkelse der det inngikk spørsmål om alkoholbruk. Vi fant at selvrapportert alkoholkonsum utgjorde rundt $40 \%$ av salgsvolumet. På grunn av de spesielle forhold når det gjelder alkoholomsetning på Svalbard er det grunn til å anta at estimatet i denne studien er mer pålitelig sammenlignet med tilsvarende studier fra andre områder.
\end{abstract}

\section{Høyer G, Nilssen O, Brenn T, Schirmer H. The reliability of self-reported alcohol consumption.}

The Svalbard study 1988-89. Nor J Epidemiol 1996; 6 (1): 109-113.

\section{ENGLISH SUMMARY}

The Norwegian island of Spitzbergen, Svalbard offers a unique setting for validation studies on self-reported alcohol consumption. No counterfeit production or illegal import exists, thus making a complete registration of all sources of alcohol possible. In this study we recorded sales from all agencies selling alcohol on Svalbard over a two month period in 1988. During the same period all adults living permanently on Svalbard were invited to take part in a health screening. As part of the screening a self-administered questionnaire on alcohol consumption was introduced to the participants. We found that the self-reported volume accounted for approximately 40 percent of the sales volume. Because of the unique situation applying to Svalbard, the estimate made in this study is believed to be more reliable compared to other studies using sales volume to validate self-reports.

\section{INTRODUKSJON}

Alkohol spiller en vesentlig rolle, enten direkte eller indirekte, $\mathrm{i}$ forhold til en rekke sykdommer og ulykker. Det er derfor viktig i epidemiologisk forskning å få pålitelige mål for faktisk alkoholinntak der dette er relevant. Spørreskjema har vært en vanlig benyttet måte for å innhente opplysninger om alkoholkonsum, men det er et problem at alkoholkonsumet er betydelig underestimert når man legger selvrapport til grunn (1-3). De fleste studier konkluderer med at selvrapportert konsum har en dekningsgrad mellom 40 og 60 prosent sammenlignet med salgstall (4-6). Metodisk er sammenligningen mellom salgstall og selvrapportert konsum problematisk. Salgstall er bare tilgjengelig på aggregatnivå og kan ikke direkte sammenlignes med konsumpsjonsdata på individnivå. Et annet problem er at offentlige salgstall ikke omfatter alle kilder for alkohol, som for eksempel illegal produksjon eller import.

På Svalbard kan de fleste av disse problemene elimineres på grunn av de spesielle forhold som råder når det gjelder salg og bruk av alkohol. Alkohol på Svalbard er ikke avgiftsbelagt, noe som gjør at prisnivået er ca. 70 prosent lavere enn på det norske fastlandet. De lave prisene gjør at smugling eller egenproduksjon av alkohol ikke forekommer. I tillegg kommer at det er såvidt få nordmenn som bor på 
Svalbard, noe som gjøre det praktisk mulig å inkludere alle i en screeningundersøkelse. Forholdene er også meget gunstige for å få tak i komplette salgstall da det bare finnes ett utsalgssted for øl, vin og brennevin. Og på den tid studien fant sted var det også bare ett serveringssted der alkohol ble solgt i Longyearbyen, der 95 prosent av den norske befolkningen bor. På denne bakgrunn er Svalbard unik når det gjelder muligheten til å beregne en eksakt dekningsprosent av selvrapportert alkoholkonsum sammenlignet med salgstall, og dermed påliteligheten av selvrapportert konsum. Våre hovedfunn er publisert tidligere (7), og denne artikkelen er en omarbeidet og forkortet versjon av dette arbeidet.

\section{MATERIALE OG METODE}

Svalbardstudien var i hovedsak en generell helseundersøkelse rettet mot risiko for hjerte-kar sykdommer etter samme mønster som fylkesundersøkelsene i regi av Statens Helseundersøkelser (SHUS). Alle norske innbyggere, 18 år eller eldre, ble invitert til å delta forutsatt at de hadde, eller forventet å ha, minst 6 måneders opphold på Svalbard. De som deltok gjennomgikk en enkel undersøkelse der det også ble tatt blodprøver. Blodprøvene inkluderte måling av HDL kolesterol og gamma-glutamyltransferase (GGT), som er en tradisjonell markør for alkoholkonsum. Deltakerne måtte også fylle ut to spørreskjema, der det andre ("Svalbardskjema") inneholdt seks spørsmål om alkoholforbruk. Det første spørsmålet spurte om respondenten var totalavholdende eller ikke. De ikke totalavholdende ble spurt hvor ofte de drakk øl, vin og brennevin (svarkategorier: aldri eller få ggr. årlig, 1-2 ggr. i måneden, 1 gang i uka, 2-3 ggr. i uka, daglig). Videre ble de bedt om å angi mengde inntatt øl, vin og brennevin siste uke. Ukekonsumet ble registrert som alkoholenheter, der 1 enhet var definert som 15 gram alkohol (1.9 cl ren alkohol), og respondentene ble vist illustrasjoner til hjelp for å regne om vanlige alkoholdrikker til alkoholenheter. Endelig ble det spurt hvor ofte de hadde vært beruset siste 12 måneder, der beruset ble definert som et inntak av mer enn 5 flasker øl, 1 flaske vin eller tilsvarende i én drikkeepisode (svarkategorier: aldri, få ggr., 1-2 ggr. i måneden, 1-2 ggr. i uka, mer enn 1-2 ggr. i uka). Spørsmålene om drikke- og beruselsesfrekvens har vært brukt i norske populasjonsstudier $(8,9)$, mens spørsmålene om ukekonsum er utarbeidet på bakgrunn av retningslinjer fra Rusmiddeldirektoratet (10). Datainnsamlingen fant sted i oktober og november 1988. Dette tidspunktet er også foretrukket av Statens Institutt for Alkoholforskning (SIFA), da perioden anses som representativ for alkoholinntak på årsbasis (6).

Salgstall fra alle salgssteder ble registrert for de samme månedene som øvrige data ble innsamlet. Fra utsalget for vin og brennevin fikk vi også oppgaver over hva som ble solgt til turister, fiskere og andre med tilfeldig opphold på Svalbard, slik at vi kunne regne ut netto salg til nordmenn som bodde permanent på Svalbard i perioden. Salg til andre enn fastboende kunne registreres nøyaktig fordi disse må presentere enten flybillett eller rekvisisjon fra sysselmannen for å handle alkohol. Vi registrerte også totalsalg fra puben/restauranten ("Huset") samt salgstall for øl fra Svalbardbutikken. Oppgaver over privat direkte import av alkohol fra fastlandet til Svalbard ble gitt av Vinmonopolet som formidler alt slikt salg. For å justere salgstall fra "Huset" ble volumet redusert med den samme andel som salg til ikke fastboende representerte når det gjaldt salg av vin og brennevin, mens salg av øl fra Svalbardbutikken ble redusert med bare 5\%, da salg av øl til ikke-fastboende er vanskeliggjort ved at det krever skriftlig tillatelse fra sysselmannen, og forekommer derfor sjeldent.

Alle mål for alkohol ble regnet om til liter ren alkohol. For øl benyttet vi en gjennomsnittlig alkohol volumprosent på 4,4, mens tilsvarende volumprosenter for bordvin, hetvin og brennevin ble satt til henholdsvis 10,5, 18 og 43. For å beregne dekningsgraden, definert som forholdet mellom selvrapportert konsum og salgstall (faktisk konsum), regnet vi ut forholdet mellom gjennomsnittlig konsum for alle som svarte på alkoholspørsmålene og per capita salgsvolum.

Totalt ble 818 personer invitert til å delta i undersøkelsen. Alders- og kjønnsfordeling er vist i tabell 1 , som også viser antall personer som møtte til undersøkelsen og antallet som fylte ut "Svalbardskjemaet". Svalbardbefolkningen er relativt ung med en gjennomsnittsalder på 37,1 år for menn og 35,2 år for kvinner, og det er en klar mannsdominans (kvinner utgjorde bare $35,2 \%$ av befolkningen). Antall personer som møtte og besvarte et eller flere av alkoholspørsmålene var 513 (331 menn og 182 kvinner). Aldersgrupperinger er gjort identisk med den inndeling SIFA bruker i sine befolkningsstudier. Resultatene er statistisk analysert ved hjelp av kji-kvadrat, t-tester og regresjonsanalyser.

\section{RESULTATER}

I henhold til selvrapport ble det i registreringsuken konsumert 3284 alkoholenheter. Dette svarer til et gjennomsnittlig per capita konsum på 6,25 liter ren alkohol per år basert på de personer som besvarte alkoholspørsmålene $(n=513)$. Detaljerte opplysninger om selvrapportert konsum er vist i tabell 2. Menn rapporterte et gjennomsnittlig konsum på 8,01 liter, mens tilsvarende volum for kvinner var 3,03 liter. Det høyeste konsumpsjonsnivåt ble funnet $\mathrm{i}$ aldersgruppen 21-30 år for begge kjønn. Tabell 3 viser gjennomsnittlig per capita konsum for forskjellige alkoholtyper $\mathrm{i}$ henhold til både selvrapport og salgstall. Som 
Tabell 1. Personer inkludert i Svalbardstudien etter kjønn og deltakelse i ulike deler av studien.

\begin{tabular}{|c|c|c|c|c|c|c|c|c|c|}
\hline \multirow[b]{4}{*}{ Personer } & \multirow{2}{*}{\multicolumn{3}{|c|}{ Menn }} & \multirow{2}{*}{\multicolumn{3}{|c|}{ Kvinner }} & \multirow{2}{*}{\multicolumn{3}{|c|}{ Total }} \\
\hline & & & & & & & & & \\
\hline & \multirow[b]{2}{*}{$\mathrm{N}$} & \multicolumn{2}{|c|}{ Gjennomsn. } & \multicolumn{3}{|c|}{ Gjennomsn } & \multirow[b]{2}{*}{$\mathrm{N}$} & \multicolumn{2}{|c|}{ Gjennomsn. } \\
\hline & & $\%$ & alder & $\mathrm{N}$ & $\%$ & alder & & $\%$ & alder \\
\hline Invitert & 530 & 100 & 37.1 & 288 & 100 & 35.2 & 818 & 100 & 36.4 \\
\hline $\begin{array}{l}\text { Møtte til } \\
\text { undersøkelsen }\end{array}$ & 388 & 73 & 38.4 & 224 & 78 & 35.2 & 612 & 75 & 37.3 \\
\hline $\begin{array}{l}\text { Returnerte Svalbard- } \\
\text { spørreskjema }\end{array}$ & 333 & 63 & 38.8 & 184 & 64 & 35.2 & 517 & 63 & 37.5 \\
\hline $\begin{array}{l}\text { Besvart alkohol- } \\
\text { spørsmålene }\end{array}$ & 331 & 63 & 38.6 & 172 & 63 & 35.2 & 513 & 63 & 37.4 \\
\hline
\end{tabular}

Tabell 2. Gjennomsnittlig selvrapportert alkoholkonsumpsjon (liter ren alkohol per capita per år) etter kjønn og aldersgrupper.

\begin{tabular}{|c|c|c|c|c|c|c|c|c|c|c|}
\hline \multirow[b]{2}{*}{ Alder } & \multicolumn{5}{|c|}{ Menn } & \multicolumn{5}{|c|}{ Kvinner } \\
\hline & $\mathrm{N}$ & $\varnothing 1$ & vin & br.vin & total & $\mathrm{N}$ & $\varnothing 1$ & vin & br.vin & total \\
\hline $18-20$ & 7 & 2.09 & 0 & 1.25 & 3.34 & 7 & 2.30 & 0.70 & 0 & 2.00 \\
\hline $21-30$ & 78 & 4.51 & 0.74 & 3.41 & 8.66 & 55 & 0.69 & 1.64 & 1.08 & 3.41 \\
\hline $31-50$ & 188 & 3.24 & 1.34 & 4.29 & 8.87 & 108 & 0.81 & 1.52 & 0.68 & 3.01 \\
\hline $51+$ & 52 & 1.88 & 0.96 & 2.61 & 5.45 & 10 & 0.10 & 1.56 & 0.30 & 1.96 \\
\hline Alle & 331 * & 3.25 & 1.09 & 3.67 & 8.01 & $182 *$ & 0.78 & 1.50 & 0.75 & 3.03 \\
\hline
\end{tabular}

* Inkludert 6 menn og 2 kvinner der alder er ukjent.

Tabell 3. Selvrapportert konsumpsjon og registrerte salgstall av ulike alkoholtyper (liter ren alkohol per capita og år) samt dekningsgrad i prosent*. Svalbard 1988-89.

\begin{tabular}{lcccr} 
& $\varnothing 1$ & vin & br.vin & total \\
\cline { 2 - 5 } Selvrapportert konsumpsjon & 2.37 & 1.23 & 2.64 & 6.25 \\
Registrert salgsvolum & 4.34 & 2.24 & 9.58 & 16.17 \\
Dekningsgradt & 54.6 & 54.9 & 27.6 & 38.7 \\
\hline * Alle menn og kvinner 18 år eller eldre er inkludert. \\
$\begin{array}{l}\text { † Dekningsgraden er definert som forholdet mellom selvrapportert } \\
\text { alkoholkonsum og registret salgsvolum. }\end{array}$
\end{tabular}

tabellen viser er det gjennomsnittlige per capita salgsvolum 16,17 liter ren alkohol. Dette gir en total dekningsgrad på 38,7\%. Dekningsgraden varierte for ulike alkoholtyper, der dekningsgraden for øl (54,6\%) og vin $(54,9 \%)$ var høyere enn for brennevin $(27,6 \%)$.

GGT viste ingen signifikant korrelasjon med ukentlig selvrapportert alkoholinntak i en regresjonsanalyse, der vi benyttet log-transformert GGT som avhengig variabel. Når vi brukte ukentlig selvrapportert alkoholinntak som avhengig variabel, både utransformert og log-transformert, var denne for begge kjønn signifikant korrelert med frekvens av inntak av alle alkoholtyper samt med beruselsesfrekvens.

\section{DISKUSJON}

Hensikten med denne studien har vært å validere selvrapportert alkoholkonsum ved å sammenligne selvrapport med gjennomsnittlig per capita salgsvolum. Forutsatt at salgsvolum er et adekvat mål for faktisk inntatt volum, representerer selvrapportert volum i denne studien mindre enn halvparten av hva som faktisk ble kjøpt. Et vesentlig spørsmål i denne sammenheng er imidlertid om gjennomsnittlig salgsvolum er et godt mål for hva som faktisk drikkes av respondentene i befolkningsstudier. Modellen bygger videre på at ikke-respondenter har samme drikkemøn- 
ster som respondentene. Det foreligger studier som konkluderer med at dette ikke er tilfelle, og at ikkerespondenter drikker mer enn respondenter i surveyundersøkelser (11-14), mens andre har konkludert med at ikke-respondentene ikke utgjør noen bias i alkohol-surveys (6). Basert på labaoratoriedata og lokalt kjennskap til befolkningen på Svalbard har vi ikke holdepunkter for at drikkemønsteret hos dem som ikke svarte på alkoholspørsmålene er slik at det ville ha endret den dekningsprosenten vi har funnet $\mathrm{i}$ denne studien.

Det kan videre reises spørsmål om registrert salgsvolum er et pålitelig mål for hva som faktisk drikkes. Minst to feilkilder kan gjøre seg gjeldende i denne sammenheng. Den første er om det drikkes alkohol fra andre kilder enn dem som inngår i registrert salgstall, den andre er om det som kjøpes faktisk drikkes på Svalbard. Da smugling eller ulovlig hjemmeproduksjon av alkohol som nevnt er ukjent på Svalbard, kan den første feilkilden med stor sannsynlighet elimineres. Dette bekreftes av politirapportene, der det fremgår at det aldri har vært reagert strafferettslig på slike forhold (personlig meddelelse fra sysselmannsetaten). Legal produksjon av vin eller øl er også ukjent på Svalbard. Likevel står vi tilbake med alkohol som bosatte på Svalbard drikker ved fravær fra øygruppa. På grunn av Svalbards avsides beliggenhet, reiser ikke fastboende så ofte til utlandet som andre nordmenn. Videre er de månedene da screeningen foregikk preget av lav reiseaktivitet. På dette grunnlaget er det lite sannsynlig at alkohol inntatt utenfor Svalbard (og derved ikke inkludert $i$ våre salgstall) skulle ha noen vesentlig betydning for de estimatene som er gjort $i$ denne studien.

Spørsmålet om hvorvidt den alkoholen som kjøpes faktisk drikkes er mer komplisert. Er det for eksempel en "lekkasje" fra Svalbard til det norske fastlandet? Vi har ikke noen sikker kjennskap til om dette skjer, men det ble hevdet i uformelle samtaler at det ikke er uvanlig å ta med en flaske brennevin som gave ved besøk på fastlandet. At alkohol videreselges til fiskere, turister eller andre avvises derimot bestemt. Det er umulig å anslå størrelsen av en eventuell "lekkasje" i form av gaver, men dersom dette har betydning vil det redusere det volumet vi hevder faktisk er konsumert av personer bosatt på Svalbard. Den lavere dekningsprosent for brennevin sammenlignet med øl og vin, kan tyde på at individuell eksport av gavebrennevin er en realitet. En annen forklaring kan være en mindre grad av standardisering for brennevininntak i private sammenkomster sammenlignet med inntak av øl og vin. Vi vet at det meste av brennevinsinntaket skjer i private sammenhenger, og at en brennevinsdrink og derved alkoholinnhold kan variere betydelig i størrelse ved slike omstendigheter. Av betydning er det også at man som regel blir mer beruset når man drikker brennevin og derfor har dårligere hukommelse for hva man faktisk har drukket. På Svalbard drikkes relativt mer av det totale alkoholkonsum som brennevin sammenlignet med fastlandet (15), noe som gjør at manglende standardisering og hukommelsesbias i større grad kan påvirke selvrapportert konsum på Svalbard.

En annen "lekkasje" kan være alkohol som blir drukket av ungdom. Selv om man må være over 18 år for å få kjøpt øl og vin, og 20 år for brennevin på Svalbard som på fastlandet, er det godt dokumentert fra undersøkelser på fastlandet at mindreårige drikker alkohol (1). Da det er få tenåringer som bor på Svalbard, og fordi den sosiale kontroll er meget sterk antas dette forholdet ikke å spille noen viktig rolle.

Alt i alt virker det rimelig å anvende salgsvolum som mål for faktisk inntatt alkohol, ettersom de faktorene som kan tenkes å influere på dette forholdet synes å spille liten eller ingen rolle på Svalbard. I en annen studie fra fastlandet fant man en dekningsgrad på 55,9\% ved å sammenligne selvrapport og offentlige salgstall (2). Ved å inkludere ikke registrert konsum (smugling, hjemmeproduksjon og inntatt $\mathrm{i}$ utlandet) falt dekningsgraden til $42 \%$. Selv om feilkildene ved vår undersøkelse er mindre er det betryggende at de to dekningsgradene er såpass like. På bakgrunn av disse studiene er det rimelig å forvente en dekningsgrad på rundt $40 \%$ når man benytter selvadministrerte spørreskjema for innhenting av alkoholkonsumpsjonsdata.

\section{KONKLUSJON}

Dekningsgraden av selvrapportert alkoholinntak sammenlignet med salgstall ble i denne studien fra Svalbard funnet å være i underkant av 40\%. På grunn av de spesielle forhold når det gjelder alkoholomsetning på Svalbard er det grunn til å anta at estimatet $i$ denne studien mer pålitelig enn tilsvarende studier fra andre områder.

\section{REFERANSER}

1. Brun-Guldbrandsen S. Drinking habits in Norway. I: Skog OJ, Waalberg R, red. Alcohol and Drugs: The Norwegian Experience. Oslo: Statens Institutt for Alkoholforskning, 1988.

2. Nordlund S. Metoder og metodeproblemer ved estimering av alkoholforbruk. Oslo: SIFA rapport nr. 3/92, 1992.

3. Single E, Wortley S. A comparison of alternative measures of alcohol consumption in the Canadian national survey of alcohol and drug use. Addiction 1994; 89: 395-9. 
4. Midanik L. The validity of self-reported alcohol consumption and alcohol problems: A literature review. British Journal of Addiction 1982; 77: 375-82.

5. Midanik L. Validity of self-reported alcohol use: A literature review and assessment. British Journal of Addiction 1988; 83: 1019-29.

6. Nordlund S. Data om alkohol og andre stoffer 1985. Oslo: SIFA rapport nr. 1/87, 1987.

7. Høyer G, Nilssen O, Brenn T, Schirmer H. The Svalbard study 1988-89: a unique setting for validation of self-reported alcohol consumption. Addiction 1995; 90: 539-44.

8. Brenn T. The Tromsø heart study: alcoholic beverages and coronary risk factors. Journal of Epidemiology and Community Health 1986; 40: 249-56.

9. Nilssen O, Førde OH. Seven-year longitudinal population study of change in gamma-glutamyltransferase: The Tromsø Study. American Journal of Epidemiology 1994; 139: 787-92.

10. Hvordan drikke mindre alkohol. En praktisk veiledning. Oslo: Statens edruskapsdirektorat, 1986.

11. Reinås KT. Alkoholens kilder. Nordmenns totale alkoholforbruk i 1989. Oslo: Rusmiddeldirektoratet, 1991.

12. Popham RE, Schmidt W. Words and deeds: The validity of self-report data on alcohol consumption. Journal of Studies on Alcohol 1981; 42: 355-8.

13. Øjesjø L, Hagnell O. Prevalence of male alcoholism in a cohort observed for 25 years. Scandinavian Journal of Social Medicine 1980; 8: 55-61.

14. Jacobsen BK. Frequency of alcohol use and the level of education. Journal of Internal Medicine 1989; 225: 417-22.

15. Høyer G, Nilssen O, Brenn T, Schirmer H. Nordmenn og billig alkohol: alkoholkonsum i et norsk lavprisområde. Nordisk Alkohol Tidsskrift 1994; 11: 139-45. 